\title{
Surveillance of Wisconsin Organisms for Trends in Antimicrobial Resistance and Epidemiology (SWOTARE): 20 I 8-20 I 9 Report on Enterobacter cloacae and Klebsiella pneumoniae Clinical Isolates
}

\author{
Alyssa Reynoso, BS and Erik Munson, PhD
}

Objectives: Both Enterobacter cloacae and Klebsiella pneumoniae have been regarded as important opportunistic pathogens for humans. Recent data have described the spread of multi-resistant strains of these organisms. Development of novel resistance phenotypes may result in a reduction in anti-infective efficacy, therefore making patient treatment decisions challenging. The Surveillance ofWisconsin Organisms for Trends in Antimicrobial Resistance and Epidemiology (SWOTARE) program aims to combat this issue and improve antibiotic stewardship by monitoring antimicrobial resistance at a local level.

Design: Multi-center laboratory surveillance, with testing at a single location utilizing standardized media and susceptibility testing protocols

Methods: In the years 2018 and 2019, a total of 591 clinically-significant E. cloacae and 668 clinically-significant $K$. pneumoniae isolates were collected through this initiative; limited demographic data were also supplied. Isolates were tested by broth microdilution procedures advocated by Clinical and Laboratory Standards Institute.

Results: On a statewide level, both $E$. cloacae and $K$. pneumoniae demonstrated in vitro potency to carbapenem and aminoglycoside agents at rates exceeding $96 \%$. K. pneumoniae isolates were generally more susceptible to cephem and monobactam agents than $E$. cloacae isolates; the converse was true for fluoroquinolone agents. Patterns of local antimicrobial resistance were revealed that were not apparent at the state level. E. cloacae isolates submitted from the Northcentral and Southeast regions demonstrated decreased susceptibility to five antimicrobial agents (notably third- and fourth-generation cephems) when compared to the state average. Isolates derived from males, older individuals, and urogenital sources exhibited decreased susceptibility to third- and fourth-generation cephem agents $(P \leq 0.047)$. With respect to $K$. pneumoniae, antimicrobial resistance phenotype was not a function of geography or gender. However, isolates emanating from older patients and the respiratory tract showed decreased susceptibility to ampicillin/sulbactam and cefazolin, respectively $(P \leq 0.019)$.

Conclusions: Antimicrobial resistance surveillance at a local level provides utility to community/rural hospital clinicians, pharmacists, and infection control practitioners. With respect to $E$. cloacae, further surveillance efforts may be necessary in the Northcentral and Southeast regions ofWisconsin. Subanalysis of demographic data indicated cephem-resistance correlates that are not apparent at the statewide level.

Keywords: Enterobacter cloacae; Klebsiella pneumoniae; Surveillance; Antimicrobial resistance; Wisconsin

Corresponding Author: Erik Munson, PhD, Department of Medical Laboratory Science, Marquette University, PO Box 188I, Milwaukee, Wisconsin 5320I- I88I, Tel: (4I4) 288-5848, Fax: (4I4) 288-7948, Email: erik.munson@marquette.edu

Funding: This research received support from the Wisconsin Department of Health Services, Division of Public Health (ELC Project K2: HAI Coordinated Prevention and Stewardship).
Received: June 8, 2020

Revised: March 14,2021

Accepted: April 22, 2021

doi: $10.3121 / \mathrm{cmr} .2021 .1588$ 
$\mathrm{T}$ The paradigm of antimicrobial resistance is one that requires considerable attention. In 2019, this subject was deemed by the Centers for Disease Control and Prevention (CDC) as the greatest global health crisis to affect all forms of life. ${ }^{1}$ More than 2.8 million antibiotic-resistant infections occur in the United States annually, with greater than 35,000 individuals dying as a result. ${ }^{1}$ Moreover, the CDC has classified the antimicrobial resistance profiles of carbapenemresistant Acinetobacter spp., Candida auris, Clostridioides difficile, carbapenem-resistant Enterobacterales (CRE), and drug-resistant Neisseria gonorrhoeae as being urgent threats to human health and requiring aggressive intervention. These organisms (three of which are Gram-negative bacteria) promulgate the spread of resistance by consistently developing new resistance mechanisms and potentially exchanging these resistance determinants with other bacteria.

Enterobacter cloacae and Klebsiella pneumoniae are of major concern in health care settings, as these organisms are leading causes of nosocomial infections worldwide., ${ }^{2,3}$ Beyond the very urgent CRE threat, an additional paradigm related to these organisms that raises serious epidemiologic and transmission concerns is extended-spectrum beta-lactamase production..$^{1-3}$ These resistance mechanisms have compromised the treatment of common infections. With available antimicrobial agents becoming less efficacious, infections caused by these strains become more severe, with some being nearly impossible to treat. ${ }^{4}$

Recognizing that no "one size fits all" approach exists to optimize antimicrobial administration in all clinical settings, ${ }^{5}$ the Surveillance of Wisconsin Organisms for Trends in Antimicrobial Resistance and Epidemiology (SWOTARE) program was initiated in 2016 to identify local emerging

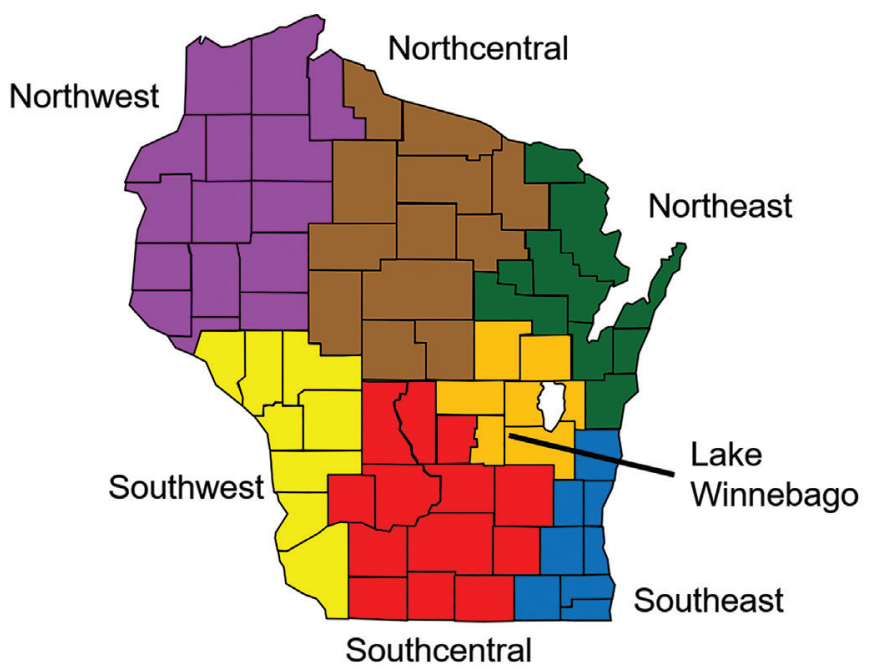

Figure 1. Distribution of seven Wisconsin geographic regions defined by the SWOTARE program, 2018-2019. antimicrobial resistance patterns throughout regions of Wisconsin and to inform prevention efforts toward curtailing resistance spread in those areas. ${ }^{6,7}$ The purpose of the presented SWOTARE investigation was to create a statewide antibiogram for E. cloacae and $K$. pneumoniae and to elucidate potential regional and demographic factors associated with antimicrobial resistance in these organisms.

\section{Materials and Methods}

\section{Study Site Recruitment}

The seven bioterrorism preparedness regions of the Wisconsin Clinical Laboratory Network, as established in $2001,{ }^{8}$ served as the basis for geographic comparison within this study (Figure 1). Three study sites were chosen from each region for provision of bacterial isolates. To prevent potential bias from larger population centers, two hospital microbiology laboratories from more rural areas and one from an area of higher population within the region were selected. Study locations included microbiology laboratories in Eau Claire, Spooner/Ashland, and St. Croix Falls/Amery/Cumberland (Northwest region); Stevens Point, Marshfield, and Weston (Northcentral region); Green Bay (two locations) and Manitowoc (Northeast region); La Crosse, Platteville/Prairie $\mathrm{du}$ Chien, and Viroqua (Southwest region); Madison, Janesville/ Monroe, Fort Atkinson (Southcentral region); Fond du Lac, Neenah, Appleton (Lake Winnebago region); and Milwaukee, West Allis, West Bend (Southeast region). Limitations to this approach included regions with increased population density, regions with fewer hospital microbiology laboratories, and regions that experienced increased laboratory testing consolidation in general. The Southeast, Northeast, and Lake Winnebago regions were represented by fewer than two rural laboratories. During a previously-described 2018 surveillance effort, $73 \%$ of participating hospital microbiology laboratories were derived from municipalities with populations $<15,000$ (per 2016 census estimates), with an aggregate 57\% of laboratories residing in municipalities with populations $<30,000$.

\section{Selection of Isolates}

During both calendar years 2018 and 2019, study sites were requested to forward between 11 and 18 clinically-significant isolates of $K$. pneumoniae and E. cloacae on Amies transport swabs containing charcoal (Hardy Diagnostics, Santa Maria, California) to a centralized testing laboratory. To limit potential of bias during the collection process, isolates were collected in consecutive fashion, and any duplicate or nonviable isolates were excluded from the study. In addition, study sites were asked to provide limited demographic information related to age, gender, specimen source of isolate, and location of healthcare encounter. Access to protected health information for the purpose of surveillance was granted by the Marquette University Institutional Review Board. Because of the lack of direct involvement in the collection of specimens, and because of the utilization of de-identified isolates from routine clinical 
care, the SWOTARE program was not considered to be actively engaged in human subjects research by the Marquette University Institutional Review Board.

\section{Test Performance}

Following cultivation of isolates from transport swabs and subculture onto trypticase soy agar with 5\% sheep erythrocytes (ThermoFisher Remel, Lenexa, Kansas), broth microdilution antimicrobial susceptibility testing was performed at a centralized laboratory and interpreted using standards published by the Clinical and Laboratory Standards Institute (CLSI). ${ }^{9,10}$ CLSI revised its fluoroquinolone minimum inhibitory concentration (MIC) breakpoints in its 2019 update,${ }^{11}$ and data derived from isolates collected and tested in 2019 were interpreted per the revised guidelines. Levofloxacin and ciprofloxacin MIC values derived from isolates collected and tested in 2018 were subsequently re-interpreted using current CLSI breakpoints ${ }^{11}$ to allow for inclusion in this report.

\section{Data Analysis}

Percentage susceptible, intermediate, and resistant values, as well as median $\mathrm{MIC}\left(\mathrm{MIC}_{50}\right)$ and 90th percentile $\mathrm{MIC}\left(\mathrm{MIC}_{90}\right)$ determinations were made on a statewide, geographic, and epidemiologic basis. To characterize geographic variation, the statewide mean susceptibility percentage for a given organism/antimicrobial combination established a baseline value. An interval of $5 \%$ on either side of that mean represented normal distribution. Region-specific values $\geq 5 \%$ less than the state mean indicated areas with increased resistance. Region-specific values $\geq 5 \%$ greater than the state mean indicated less resistance potential. These intervals were utilized in previous SWOTARE reports. ${ }^{6,7,12}$ The significance test of proportions determined if differences in susceptibility percentage among epidemiologic comparisons were significant. An a priori decision was made to examine statistical significance using a two-tailed test with an alpha level of 0.05 .

\section{Results}

Wisconsin E. cloacae and K. pneumoniae Antibiogram

An aggregate 591 and 668 isolates of E. cloacae and K. pneumoniae, respectively, were forwarded to SWOTARE during the study period. There were 277 (46.9\%) and 314 $(45.5 \%)$ of the E. cloacae and K. pneumoniae isolates, respectively, collected in 2018. Aggregate percentage contribution by region to total collection ranged from $13.0 \%$ to $15.0 \%$ for K. pneumoniae and from $11.2 \%$ to $16.2 \%$ for E. cloacae.

Carbapenems and aminoglycosides retained substantial in vitro potency for both $E$. cloacae and K. pneumoniae isolates in Wisconsin with $>96 \%$ susceptibility (Table 1). Fluoroquinolone agents exhibited slightly less in vitro potency against $K$. pneumoniae isolates when compared to E. cloacae. Both E. cloacae and $K$. pneumoniae isolates were approximately $92 \%$ susceptible to trimethoprim-sulfamethoxazole. Selected cephems exhibited less in vitro activity against both organisms, particularly E. cloacae. Noteworthy findings include $85.8 \%$ and $77.8 \%$ susceptibility rates of E. cloacae to ceftazidime and ceftriaxone, respectively. K. pneumoniae demonstrated $<90 \%$ susceptibility to first- and second-generation cephem agents. E. cloacae isolates also exhibited $<90 \%$ susceptibility to aztreonam.

\section{Geographic Variability Relative to E. cloacae and K. pneumoniae Susceptibility}

E. cloacae isolates from the Northcentral and Southeast regions demonstrated decreased susceptibility to five antimicrobial agents when compared to statewide profiles. Aztreonam $\mathrm{MIC}_{90}$ values for Northcentral isolates and levofloxacin $\mathrm{MIC}_{90}$ values for Southeast isolates both increased when compared to state profiles (Table 2). The ceftazidime susceptibility rate in the Northcentral region $(80.0 \%$ ) varied from the Wisconsin average (Figure 2A), while similar findings were noted for ceftriaxone susceptibility in the Northcentral $(70.7 \%)$

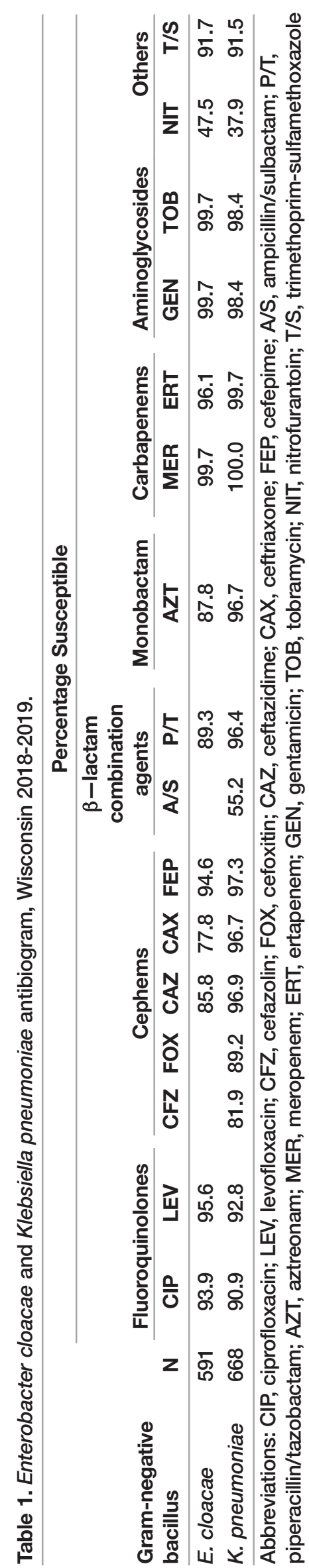


Table 2. Selected foci of decreased Enterobacter cloacae and Klebsiella pneumoniae susceptibility, Wisconsin 2018-2019.

\begin{tabular}{|c|c|c|c|c|c|c|c|}
\hline \multirow[b]{2}{*}{ Organism } & \multirow[b]{2}{*}{ Region } & \multirow[b]{2}{*}{$\begin{array}{l}\text { Antimicrobial } \\
\text { agent }\end{array}$} & \multicolumn{3}{|c|}{ Region-specific Data } & \multicolumn{2}{|c|}{ Wisconsin Data } \\
\hline & & & $\begin{array}{l}\text { Percentage } \\
\text { susceptible }\end{array}$ & $\begin{array}{l}\mathrm{MIC}_{50} \\
(\mu \mathrm{g} / \mathrm{ml})\end{array}$ & $\begin{array}{l}\mathrm{MIC}_{90} \\
(\mu \mathrm{g} / \mathrm{ml})\end{array}$ & $\begin{array}{l}\mathrm{MIC}_{50} \\
(\mu \mathrm{g} / \mathrm{ml})\end{array}$ & $\begin{array}{c}\mathrm{MIC}_{90} \\
(\mu \mathrm{g} / \mathrm{ml})\end{array}$ \\
\hline \multirow{6}{*}{ E. cloacae } & \multirow{3}{*}{ Northcentral $^{\mathrm{a}}$} & Ceftazidime & 80.0 & $\leq 2$ & $>64$ & $\leq 2$ & 64 \\
\hline & & Ceftriaxone & 70.7 & $\leq 0.5$ & $>8$ & $\leq 0.5$ & $>8$ \\
\hline & & Aztreonam & 81.3 & $\leq 2$ & 64 & $\leq 2$ & 32 \\
\hline & \multirow{3}{*}{ Southeast ${ }^{\mathrm{b}}$} & Levofloxacin & 90.6 & $\leq 0.25$ & 0.5 & $\leq 0.25$ & $\leq 0.25$ \\
\hline & & Ceftriaxone & 70.8 & $\leq 0.5$ & $>8$ & $\leq 0.5$ & $>8$ \\
\hline & & Cefepime & 89.6 & $\leq 1$ & 4 & $\leq 1$ & $\leq 1$ \\
\hline \multirow{4}{*}{ K. pneumoniae } & \multirow[t]{2}{*}{ Northwest ${ }^{c}$} & $\begin{array}{l}\text { Ampicillin/ } \\
\text { sulbactam }\end{array}$ & 49.4 & 16 & 16 & 8 & 32 \\
\hline & & Cefazolin & 80.5 & 2 & 4 & 2 & 8 \\
\hline & \multirow{2}{*}{$\begin{array}{l}\text { Lake } \\
\text { Winnebago }^{d}\end{array}$} & $\begin{array}{l}\text { Ampicillin/ } \\
\text { sulbactam }\end{array}$ & 50.0 & 8 & 64 & 8 & 32 \\
\hline & & Cefazolin & 79.8 & 2 & 16 & 2 & 8 \\
\hline
\end{tabular}

a75 E. cloacae isolates; b96 E. cloacae isolates; ' $87 \mathrm{~K}$. pneumoniae isolates; d94 K. pneumoniae isolates

and Southeast regions (70.8\%; Figure 2B). Additionally, the ceftazidime $\mathrm{MIC}_{90}$ value for Northcentral E. cloacae isolates trended upward when compared to the state profile (Table 2). In contrast, increased susceptibility of E. cloacae isolates to ceftriaxone was observed in the Northwest and Lake Winnebago regions $(83.3 \%$ and $84.0 \%$, respectively; Figure $2 \mathrm{~B})$. The cefepime susceptibility rate from the Southeast region $(89.6 \%)$ also differed from the Wisconsin average (Fig. 2C); moreover, the cefepime $\mathrm{MIC}_{90}$ value specific to Southeast region $E$. cloacae isolates was elevated $(4 \mu \mathrm{g} / \mathrm{ml})$ when compared to the statewide value $(\leq 1 \mu \mathrm{g} / \mathrm{ml}$; Table 2$)$.

$K$. pneumoniae isolates from the Northwest and Lake Winnebago regions demonstrated decreased susceptibility to
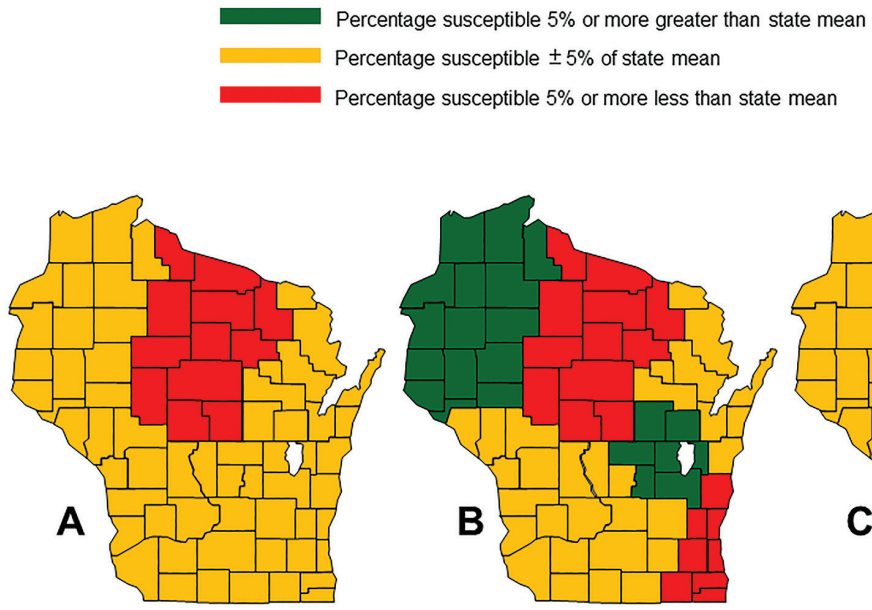
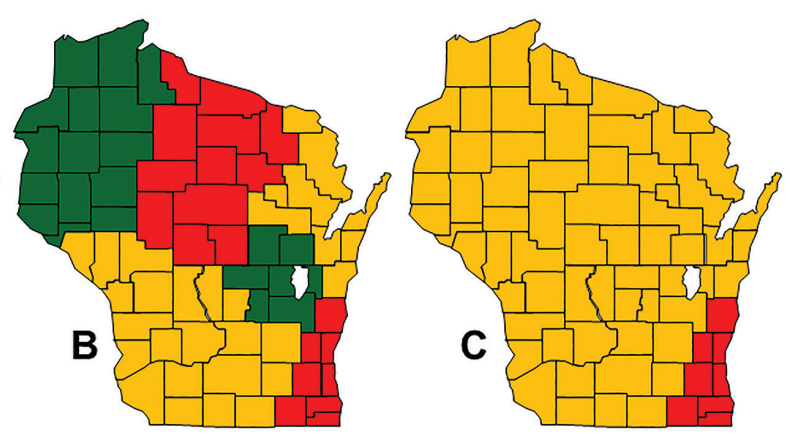

Figure 2. Geographic differences in Enterobacter cloacae susceptibility to ceftazidime (A), ceftriaxone (B), and cefepime (C), Wisconsin 2018-2019. ampicillin/sulbactam when compared to the statewide mean (55.2\% susceptibility). K. pneumoniae isolates from the Lake Winnebago region tested against cefazolin and ampicillin/ sulbactam demonstrated higher $\mathrm{MIC}_{90}$ values when compared to the statewide values (Table 2).

Variability of E. cloacae and K. pneumoniae Susceptibility Profiles as a Function of Site of Infection

E. cloacae isolates derived from urogenital sources showed decreased susceptibility to ceftazidime when compared to skin and soft tissue $(P=0.027)$ and sterile source $(P=0.011)$ isolates (Table 3). Sterile source E. cloacae isolates were derived from aspirate, blood, and bone specimens. Urogenital isolates trended toward an increased ceftazidime $\mathrm{MIC}_{90}$ ( $>64 \mu \mathrm{g} / \mathrm{ml}$ ) when compared to all $E$. cloacae isolates $(64 \mu \mathrm{g} / \mathrm{ml})$. Isolates from urogenital sources also demonstrated decreased susceptibility to aztreonam when compared to skin and soft tissue $(P=0.041)$ and sterile source $(P=0.043)$ isolates (Table 3$)$. Increased aztreonam $\mathrm{MIC}_{90}(64 \mu \mathrm{g} / \mathrm{ml})$ for urogenital E. cloacae isolates supported this finding $\left(\mathrm{MIC}_{90}\right.$ of $32 \mu \mathrm{g} / \mathrm{ml}$ for all $E$. cloacae isolates).

Respiratory $K$. pneumoniae isolates demonstrated decreased susceptibility to cefazolin when compared to skin and soft tissue $(P=0.019)$, sterile source $(P$ $=0.014)$, and urogenital $(P=0.008)$ isolates (Table 3). Respiratory isolates exhibited an increased $\mathrm{MIC}_{90}$ to cefazolin $(16 \mu \mathrm{g} / \mathrm{ml})$ when compared to the entire 
Table 3. Comparative Enterobacter cloacae and Klebsiella pneumoniae susceptibility stratified by source of infection, Wisconsin 2018-2019.

\begin{tabular}{|c|c|c|c|c|c|}
\hline Organism & $\begin{array}{l}\text { Antimicrobial } \\
\text { Agent }\end{array}$ & $\begin{array}{l}\text { Specimen } \\
\text { Source }\end{array}$ & $\begin{array}{l}\text { Percentage } \\
\text { Susceptible }\end{array}$ & $\begin{array}{l}\mathrm{MIC}_{50} \\
(\mu \mathrm{g} / \mathrm{ml})\end{array}$ & $\begin{array}{c}\mathrm{MIC}_{90} \\
(\mu \mathrm{g} / \mathrm{ml})\end{array}$ \\
\hline \multirow{8}{*}{ E. cloacae } & \multirow{4}{*}{ Ceftazidime } & $\mathrm{SST}^{\mathrm{a}, \mathrm{b}}$ & 88.1 & $\leq 2$ & 16 \\
\hline & & Sterile $^{c}$ & 91.6 & $\leq 2$ & 4 \\
\hline & & Urogenital $^{\mathrm{d}}$ & $80.6^{j}$ & $\leq 2$ & $>64$ \\
\hline & & Respiratory & 83.3 & $\leq 2$ & 8 \\
\hline & \multirow{4}{*}{ Aztreonam } & SST & 89.8 & $\leq 2$ & 8 \\
\hline & & Sterile & 91.6 & $\leq 2$ & $\leq 2$ \\
\hline & & Urogenital & $83.3^{k}$ & $\leq 2$ & 64 \\
\hline & & Respiratory & 91.7 & $\leq 2$ & 4 \\
\hline \multirow{8}{*}{ K. pneumoniae } & \multirow{4}{*}{$\begin{array}{l}\text { Ampicillin/ } \\
\text { sulbactam }\end{array}$} & $\mathrm{SST}^{\mathrm{f}}$ & 58.5 & 8 & 16 \\
\hline & & Sterile $^{g}$ & 56.2 & 8 & 32 \\
\hline & & Urogenital $^{\mathrm{h}}$ & 53.9 & 8 & 16 \\
\hline & & Respiratory & 51.4 & 8 & $>64$ \\
\hline & \multirow{4}{*}{ Cefazolin } & SST & 82.9 & 2 & 4 \\
\hline & & Sterile & 82.7 & 2 & 4 \\
\hline & & Urogenital & 83.0 & 2 & 8 \\
\hline & & Respiratory & $64.9^{1}$ & 2 & 16 \\
\hline
\end{tabular}

aSkin and soft tissue; ' ${ }^{2} 236$ E. cloacae isolates; ' 107 E. cloacae isolates; ${ }^{d} 222$ E. cloacae isolates; ${ }^{\mathrm{e}} 24$ E. cloacae isolates; ${ }^{\mathrm{f}} 123$ K. pneumoniae isolates; ${ }^{9} 185 \mathrm{~K}$. pneumoniae isolates; ${ }^{\mathrm{h}} 323 \mathrm{~K}$. pneumoniae isolates; ${ }^{\mathrm{i}} 37 \mathrm{~K}$. pneumoniae isolates; ${ }^{\mathrm{P}} \mathrm{P}=0.027 \mathrm{vs}$. SST, 0.011 vs. sterile; ${ }^{k} P=0.041$ vs. SST, 0.043 vs. sterile; ' $P=0.019$ vs. SST, 0.014 vs. sterile, 0.008 vs. urogenital

state of Wisconsin $(8 \mu \mathrm{g} / \mathrm{ml})$. Respiratory isolates also showed an increased $\mathrm{MIC}_{90}$ to ampicillin/sulbactam $(>64 \mu \mathrm{g} / \mathrm{ml})$ when compared to 308 aggregate isolates derived from skin and soft tissue and sterile sources $\left(\mathrm{MIC}_{90}\right.$ of $16 \mu \mathrm{g} / \mathrm{ml}$; data not illustrated).

\section{Demographic Influences on E. cloacae and K. pneumoniae Resistance}

E. cloacae isolates derived from older patients (80+ years) demonstrated decreased susceptibility to ceftazidime when compared to 40- to 59-year-old patients ( $P=0.047$; Table 4). This finding was also supported by a comparatively higher $\mathrm{MIC}_{90}$ value. While E. cloacae derived from patients aged 60-79 years did not show significantly lower susceptibility rates $(P=0.241), \mathrm{MIC}_{90}$ values also trended higher (Table 4$)$. The $80+$ year-old demographic also yielded an increased $\mathrm{MIC}_{90}$ to aztreonam $(64 \mu \mathrm{g} / \mathrm{ml})$ when compared to all E. cloacae isolates.

K. pneumoniae isolates from 60- to 79-year-old patients revealed decreased susceptibility to ampicillin/sulbactam when compared to $80+$ year-olds $(P=0.002)$, with a $\mathrm{MIC}_{50}$ value that was elevated when compared to all $K$. pneumoniae isolates. Isolates from the 40- to 59-year-old age group revealed elevated $\mathrm{MIC}_{90}$ values for both ampicillin/sulbactam and cefazolin when compared to all tested $K$. pneumoniae.
Of 591 E. cloacae isolates tested in 2018 and 2019 (patient mean and median ages 65.6 and 68 years, respectively), 298 $(54.1 \%)$ were derived from males. These isolates demonstrated decreased susceptibility to cefepime when compared to females $(P=0.033$; data not illustrated). Such isolates yielded an increased cefepime $\mathrm{MIC}_{90}(2 \mu \mathrm{g} / \mathrm{ml})$ when compared to female isolates $(\leq 1 \mu \mathrm{g} / \mathrm{ml})$. No significant gender-related susceptibility trending was noted with other antimicrobial agents (including aztreonam). Of $668 \mathrm{~K}$. pneumoniae isolates tested (patient mean and median ages 67.2 and 71 years, respectively), 424 $(63.5 \%)$ were derived from females. No significant genderrelated susceptibility trending was noted.

\section{Discussion}

Proposals to mitigate the spread of antimicrobial resistance have centered around development of novel anti-infective agents, adherence to infection control and prevention practices, initiation and execution of antimicrobial stewardship programs, and surveillance of antimicrobial resistance patterns. ${ }^{13}$ Not only is susceptibility testing data collection inherent to the concept of routine surveillance, ${ }^{14}$ subsequent studies of disease epidemiology can further attempt to identify and track potential antimicrobial resistance threats. ${ }^{15}$ In this fashion, surveillance programs that also collect limited demographic data ${ }^{16}$ provide an additional advantage over the traditional antibiogram 
Table 4. Comparative Enterobacter cloacae and Klebsiella pneumoniae susceptibility stratified by age group, Wisconsin 2018-2019.

\begin{tabular}{|c|c|c|c|c|c|}
\hline Organism & $\begin{array}{l}\text { Antimicrobial } \\
\text { Agent }\end{array}$ & $\begin{array}{l}\text { Age Range } \\
\text { (years) }\end{array}$ & $\begin{array}{l}\text { Percentage } \\
\text { Susceptible }\end{array}$ & $\begin{array}{l}\mathrm{MIC}_{50} \\
(\mu \mathrm{g} / \mathrm{ml})\end{array}$ & $\begin{array}{l}\mathrm{MIC}_{90} \\
(\mu \mathrm{g} / \mathrm{ml})\end{array}$ \\
\hline \multirow{10}{*}{ E. cloacae } & \multirow{5}{*}{ Ceftazidime } & $0-19^{a}$ & 80.0 & $\leq 2$ & 8 \\
\hline & & $20-39^{b}$ & 82.5 & $\leq 2$ & 16 \\
\hline & & $40-59^{c}$ & 90.3 & $\leq 2$ & 4 \\
\hline & & $60-79^{d}$ & 86.5 & $\leq 2$ & 64 \\
\hline & & $80++^{e}$ & $82.1^{\mathrm{k}}$ & $\leq 2$ & 64 \\
\hline & \multirow{5}{*}{ Aztreonam } & $0-19$ & 93.3 & $\leq 2$ & 4 \\
\hline & & $20-39$ & 87.5 & $\leq 2$ & 8 \\
\hline & & $40-59$ & 90.3 & $\leq 2$ & 4 \\
\hline & & $60-79$ & 87.6 & $\leq 2$ & 16 \\
\hline & & $80+$ & 85.4 & $\leq 2$ & 64 \\
\hline \multirow{10}{*}{ K. pneumoniae } & \multirow{5}{*}{$\begin{array}{l}\text { Ampicillin/ } \\
\text { sulbactam }\end{array}$} & $0-19^{f}$ & 60.0 & 8 & 16 \\
\hline & & $20-39^{9}$ & 59.6 & 8 & 16 \\
\hline & & $40-59^{h}$ & 54.1 & 8 & 64 \\
\hline & & $60-79^{i}$ & $49.1^{1}$ & 16 & 32 \\
\hline & & $80++^{j}$ & 63.8 & 8 & 16 \\
\hline & \multirow{5}{*}{ Cefazolin } & $0-19$ & 80.0 & 2 & 8 \\
\hline & & $20-39$ & 89.4 & 2 & 8 \\
\hline & & $40-59$ & 77.4 & 2 & 16 \\
\hline & & $60-79$ & 81.1 & 2 & 4 \\
\hline & & $80+$ & 84.6 & 2 & 4 \\
\hline
\end{tabular}

a15 E. cloacae isolates; b $40 \mathrm{E}$. cloacae isolates; $\mathrm{c} 134 \mathrm{E}$. cloacae isolates; ${ }^{\mathrm{d}} 251 \mathrm{E}$. cloacae isolates; ${ }^{\mathrm{e}} 151 \mathrm{E}$. cloacae isolates; ${ }^{\mathrm{f}} 15 \mathrm{~K}$. pneumoniae isolates; ${ }^{\mathrm{i}} 47 \mathrm{~K}$. pneumoniae isolates; ${ }^{\mathrm{h}} 133 \mathrm{~K}$. pneumoniae isolates; ${ }^{2} 28 \mathrm{~K}$. pneumoniae isolates; $188 \mathrm{~K}$. pneumoniae isolates; ${ }^{\mathrm{K}} P=0.047$ vs. $40-59$ years; $P=0.002$ vs. $80+$ years

approach. As a result, focused annual surveillance efforts can complement and augment antimicrobial stewardship efforts at the local level.

Such principles have guided the SWOTARE program since its inception in 2016. Both the procurement of clinical isolates and the subsequent centralized testing (which utilizes a standardized broth microdilution reference method) seek to eliminate commercial susceptibility testing variability and potential reporting bias that may be reflected in a local hospital antibiogram. ${ }^{17-20}$ From its origin, the SWOTARE program has provided a representative outlook on Wisconsin statewide antimicrobial resistance, because its focus is not solely on organisms derived from patients residing in tertiary care facilities located in major population centers. Rather, smaller and rural hospital laboratories are actively recruited for participation in the SWOTARE program. This carries added importance based on the fact that a significant burden of nationwide antimicrobial agent utilization (with a substantial proportion in the United States Midwest) emanates from outpatient prescriptions. ${ }^{21}$ Our data reveal high in vitro susceptibility rates for both $E$. cloacae and $K$. pneumoniae when tested against aminoglycoside and carbapenem agents, with organism-specific variable susceptibility to cephem, fluoroquinolone, and monobactam agents.

Further investigation sought to elucidate geographic and demographic factors that contributed to the decreased susceptibility of the two organisms to these agents. Past SWOTARE reports have indeed chronicled geographic differences in resistance phenotypes relative to Proteus mirabilis (northern regions of Wisconsin), ${ }^{6}$ Pseudomonas aeruginosa (Southeast region of Wisconsin), ${ }^{6}$ Streptococcus pneumoniae (Southcentral region of Wisconsin), ${ }^{6}$ and Staphylococcus aureus (southern and Lake Winnebago regions of Wisconsin). ${ }^{7}$ In the current report, E. cloacae isolates derived from the Northcentral and Southeast regions showed a greater likelihood of decreased susceptibility to third- and fourthgeneration cephem agents, with susceptibility rates up to $7 \%$ less than the state average. One additional advantage of antimicrobial resistance surveillance at the isolate level (versus antibiogram compilation) is the availability of raw MIC data for the computation of MIC frequency distributions and analysis on a percentile basis. Analysis of E. cloacae isolates derived 
from the Southeast region not only revealed a cefepime percentage susceptibility rate that was 5\% less than the state average (Table 1), but also demonstrated a cefepime $\mathrm{MIC}_{90}$ value that was at least four-fold higher than the state value (Table 2). These data indeed suggest a trend toward E. cloacae resistance to fourth-generation cephem agents in Southeast Wisconsin, which should be monitored in subsequent surveillance efforts. One cannot discount a potential role for increased local population, more tertiary care centers, and proximity to mega-population regions toward increased fourthgeneration cephem resistance. Geographic-based associations with decreased susceptibility were less common with $K$. pneumoniae isolates, with northern regions of Wisconsin potentially targeted in future surveillance.

Past SWOTARE surveys have revealed additional contributory factors to the distribution of antimicrobial resistance in Wisconsin. Relative to several antimicrobial/organism combinations, emergency department encounters exhibited higher susceptibility rates than those from outpatient clinics. ${ }^{22}$ Older patients were more likely to generate isolates of $E$. coli and $P$. mirabilis exhibiting resistance to agents such as trimethoprim-sulfamethoxazole and those of the fluoroquinolone class, ${ }^{22}$ while another survey reported that rates of cefoxitinresistant $S$. aureus were higher in younger individuals. ${ }^{7}$ Specimen source largely held a non-contributory role for the delineation of resistance in E. coli, $P$. mirabilis, $P$. aeruginosa, and S. pneumoniae. ${ }^{22}$

Within the current study set of E. cloacae isolates, urogenital isolates were characterized as having decreased susceptibility to aztreonam and ceftazidime when compared to those derived from sterile sources and from skin and soft tissue sites $(P$ $\leq 0.043)$. E. cloacae isolates from older patients also exhibited decreased susceptibility to ceftazidime. With respect to $K$. pneumoniae, delineation of region and gender played a minimal role relative to antimicrobial resistance phenotype. However, isolates collected from older patients displayed decreased susceptibility to ampicillin-sulbactam, while isolates collected from the respiratory tract exhibited decreased susceptibility to cefazolin. Additional studies have attempted to delineate differences in E. cloacae and $K$. pneumoniae antimicrobial resistance on the basis of demographic factors or specimen source. As one example, with respect to fluoroquinolone susceptibility testing of a limited number of Canadian isolates, ${ }^{23}$ increased rates of resistance were noted for urine-derived $E$. cloacae when compared to those recovered from blood and respiratory sources. Increased rates of fluoroquinolone resistance were noted in adult populations when compared to pediatric populations for both E. cloacae and $K$. pneumoniae, with an approximate $9 \%$ ciprofloxacin resistance rate in $E$. cloacae isolates derived from patients aged 65 and older. A second example ${ }^{24}$ originating from China revealed that $E$. cloacae resistance rates from adult populations trended higher for ceftriaxone and cefepime, but not for ceftazidime, when compared to isolates derived from pediatric populations. In contrast, resistance rates for cephems and penicillin derivatives were significantly higher in $K$. pneumoniae pediatric isolates when compared to adult isolates. These data highlight the fact that a given study setting could impact demographic findings relative to antimicrobial resistance; they also further promote the impetus to conduct local and routine surveillance (such as that undertaken by the SWOTARE program) to augment local knowledge of antimicrobial resistance profiles.

Data in this report should be viewed in the context of potential study limitations. Potential biases inherent to antimicrobial resistance surveillance systems have been described, ${ }^{25,26}$ including reliance on a limited number of collection sites (to provide a robust number of samples), sampling bias, failure to deal with multiple occurrences, and those related to laboratory practice and procedures. The SWOTARE program attempts to overcome a number of these limitations by collaborating with a large number of collection facilities throughout the state (with low turnover percentage on an annual basis) and providing these sites with specific isolate collection guidelines. With that said, SWOTARE personnel are not shepherding the isolate collection and submission process at each site on a daily basis. The potential limitation of lower $n$ value relative to this study of $E$. cloacae and $K$. pneumoniae clinical isolates was mitigated by using a consecutive two-year sampling and testing of isolates, with subsequent aggregate data analysis. It is possible that temporal variation within a given geographic region ${ }^{12}$ could have occurred over the two-year collection period.

\section{Conclusion}

In conclusion, a 2-year Wisconsin antibiogram of clinical $E$. cloacae and K. pneumoniae isolates is herein presented. Further data analysis revealed local and demographic findings that warrant additional antimicrobial resistance surveillance efforts. Ultimately, such efforts may assist healthcare professionals in the clinical and epidemiologic management of patients.

\section{Acknowledgments}

This research received support from the Wisconsin Department of Health Services, Division of Public Health (ELC Project K2: HAI Coordinated Prevention and Stewardship). The authors are most grateful to the following individuals for collection of isolates throughout 2018 and 2019:

Jorn Bansberg, Viroqua

Sherry Barta, Green Bay

Eric Beck, PhD, Milwaukee

Tim Block, West Bend

Becky Brooks, Stevens Point

Tracy Felland, Janesville

Thomas Fritsche, MD, PhD, Marshfield

Heidi Graves, Neenah

Ashley Hoveland, St. Croix Falls

Betsy Hudson, Prairie du Chien

Ben Kaetterhenry, Appleton

Debra Kieler, Platteville 
Timothy Kramme, Milwaukee

Joshua Kropp, Weston

Kathy Lang, Ashland

Debbie Maedke, Manitowoc

Bryna Melichar, Cumberland

Jennifer Meyer, Weston

Linda Morrison, Viroqua

Brooke Olson, Marshfield

Mattie Pitts, Spooner

Ray Podzorski, PhD, Madison

Lori Reed, Amery

Andrea Roder, Green Bay

Nyssa Sheridan, Monroe

Karen Siebers, Neenah

Frances Spray-Larson, PhD, Fort Atkinson

Janelle Stearns, Eau Claire

Sarah Stoner, La Crosse

Tyler Tschanz, Eau Claire

Ellen Wirtz, Fond du Lac

Madeline Zuber, Monroe

\section{References}

1. Centers for Disease Control and Prevention. Antibiotic Resistance Threats in the United States, 2019. United States Department of Health and Human Services, Atlanta, GA. 2019.

2. Davin-Regli A, Pagès JM. Enterobacter aerogenes and Enterobacter cloacae; versatile bacterial pathogens confronting antibiotic treatment. Front Microbiol. 2015;6:392.

3. Paczosa MK, Mecsas J. Klebsiella pneumoniae: going on the offense with a strong defense. Microbiol Mol Biol Rev. 2016;80(3):629-661.

4. World Health Organization. Antibiotic Resistance. Available at: www.who.int/news-room/fact-sheets/detail/ antibiotic-resistance. Accessed 18 March 2020.

5. Centers for Disease Control and Prevention. Core Elements of Hospital Antibiotic Stewardship Programs. Available at: https://www.cdc.gov/antibiotic-use/coreelements/ hospital.html. Accessed 18 March 2020.

6. Munson E, Hueppchen E, Zeman H. Surveillance of Wisconsin Organisms for Trends in Antimicrobial Resistance and Epidemiology: introduction to the program and summary of 2016 geographic variation. WMJ. 2018;117(3):116-121 .

7. Schulte RH, Munson E. Staphylococcus aureus resistance patterns in Wisconsin: 2018 Surveillance of Wisconsin Organisms for Trends in Antimicrobial Resistance and Epidemiology (SWOTARE) program report. Clin Med Res. 2019;17(3-4):72-81.

8. Munson E, Block TK, Bowles EJ, et al. Surveillance of Wisconsin antibacterial susceptibility patterns. WMJ. 2016;115(1):29-36.
9. Clinical and Laboratory Standards Institute (CLSI). Methods for dilution antimicrobial susceptibility tests for bacteria that grow aerobically, M07. 10th ed. Wayne, PA: CLSI; 2015.

10. Clinical and Laboratory Standards Institute (CLSI). Performance standards for antimicrobial susceptibility testing, M100. 28th informational supplement. Wayne, PA: CLSI; 2018.

11. Clinical and Laboratory Standards Institute (CLSI). Performance standards for antimicrobial susceptibility testing, M100. 29th informational supplement. Wayne, PA: CLSI; 2019.

12. Zeman H, Martin R, Munson E, Schulte R. Surveillance of Wisconsin Organisms for Trends in Antimicrobial Resistance and Epidemiology (SWOTARE): summary of 2017 findings with focus on changing resistance patterns in selected antimicrobial classes. Gundersen Medical Journal. In press.

13. Centers for Disease Control and Prevention. Antibiotic Resistance Threats in the United States, 2013. United States Department of Health and Human Services, Atlanta, GA. 2013.

14. Munson E. Biographical Feature: Clyde Thornsberry, Ph.D. J Clin Microbiol. 2016;54(2):250-253.

15. World Health Organization. Global Action Plan on Antimicrobial Resistance. Available at: https://www.who. int/publications-detail/global-action-plan-on-antimicrobialresistance. Accessed 18 March 2020.

16. Fuhrmeister AS, Jones RN. The importance of antimicrobial resistance monitoring worldwide and the origins of SENTRY antimicrobial surveillance program. Open Forum Infect Dis. 2019;6(Supplement_1):S1-S4.

17. Heginbothom ML, Magee JT, Bell JL, et al. Laboratory testing policies and their effects on routine surveillance of community antimicrobial resistance. J Antimicrob Chemother. 2004;53(6):1010-1017.

18. Bantar C, Alcazar G, Franco D, et al. Are laboratory-based antibiograms reliable to guide the selection of empirical antimicrobial treatment in patients with hospital-acquired infections? J Antimicrob Chemother. 2007;59(1):140-143.

19. Ernst EJ, Diekema DJ, BootsMiller BJ, et al. Are United States hospitals following national guidelines for the analysis and presentation of cumulative antimicrobial susceptibility data? Diagn Microbiol Infect Dis. 2004;49(2):141-145.

20. Zapantis A, Lacy MK, Horvat RT, et al. Nationwide antibiogram analysis using NCCLS M39-A guidelines. J Clin Microbiol. 2005;43(6):2629-2634.

21. Hicks LA, Bartoces MG, Roberts RM, et al. US outpatient antibiotic prescribing variation according to geography, patient population, and provider specialty in 2011. Clin Infect Dis. 2015;60(9):1308-1316. 
22. Munson E, Zeman H, Hueppchen E. Surveillance of Wisconsin Organisms for Trends in Antimicrobial Resistance and Epidemiology (SWOTARE): epidemiologic correlates for 2016 surveillance isolates. Gundersen Medical Journal. 2017;10(1):41-48.

23. Karlowsky JA, Adam HJ, Desjardins M, et al; Canadian Antimicrobial Resistance Alliance. Changes in fluoroquinolone resistance over 5 years (CANWARD 2007-11) in bacterial pathogens isolated in Canadian hospitals. J Antimicrob Chemother. 2013;68(suppl 1):i39-i46.

24. Yang S, Xu H, Sun J, Sun S. Shifting trends and age distribution of ESKAPEEc resistance in bloodstream infection, Southwest China, 2012-2017. Antimicrob Resist Infect Control. 2019;8(1):61.

25. Rempel OR, Laupland KB. Surveillance for antimicrobial resistant organisms: potential sources and magnitude of bias. Epidemiol Infect. 2009;137(12):1665-1673.

26. Reynolds R, Lambert PC, Burton PR; BSAC Extended Working Parties on Resistance Surveillance. Analysis, power and design of antimicrobial resistance surveillance studies, taking account of inter-centre variation and turnover. J Antimicrob Chemother. 2008;62(Supplement 2):ii29-ii39.

\section{Author Affiliations}

Alyssa Reynoso, $B S^{*}$ and Erik Munson, $P h D^{*,+}$

${ }^{*}$ College of Health Sciences, Marquette University, Milwaukee, Wisconsin USA

'Wisconsin Clinical Laboratory Network Laboratory Technical Advisory Group, Madison, Wisconsin USA 